Article

\title{
Corruption and the Network Structure of Public Contracting Markets across Government Change
}

\author{
Mihály Fazekas ${ }^{1,2, *}$ and Johannes Wachs ${ }^{3}$ \\ ${ }^{1}$ School of Public Policy, Central European University, 1051 Budapest, Hungary; E-Mail: fazekasm@spp.ceu.edu \\ 2 School of Slavonic and East European Studies, University College London, London, WC1H OBW, UK \\ ${ }^{3}$ Chair of Computational Social Sciences and Humanities, RWTH Aachen University, 52062 Aachen, Germany; \\ E-Mail: johannes.wachs@wu.ac.at \\ * Corresponding author
}

Submitted: 13 December 2019 | Accepted: 5 February 2020 | Published: 28 May 2020

\begin{abstract}
Corruption is thought to affect developed economies to a greater degree than developing countries. However, given our limited capacity to detect corruption, it may simply be harder to detect it in countries with stronger institutions. This article sets out to address this measurement challenge and to offer a tailored approach to one particular type of corruption: high-level corruption in government contracting. We describe a recently developed method to score procurement contracts for corruption risk. Then, using micro-level data from Hungary and the Czech Republic we analyze how corruption can distort public procurement markets, mapped as networks of buyers and suppliers. Proxying for corruption using a composite index of red flags derived from contract awards, we find that public sector buyers with high corruption risk have sparser network neighborhoods, meaning that they contract with fewer suppliers than expected. We interpret our results as evidence that corruption in procurement markets is fundamentally about the exclusion of non-favored firms. Political change has a significant effect on corrupt relationships: High corruption risk buyers with sparse neighborhoods rewire their contracting relationships roughly $20-40 \%$ more extensively than other buyers across years with government turnover. The article demonstrates how the political organization of corruption distorts market competition in OECD countries.
\end{abstract}

\section{Keywords}

corruption; government change; markets; networks; political turnover

Issue

This article is part of the issue "Fighting Corruption in the Developed World: Dimensions, Patterns, Remedies" edited by Fabrizio Di Mascio (University of Turin, Italy) and Simona Piattoni (University of Trento, Italy).

(C) 2020 by the authors; licensee Cogitatio (Lisbon, Portugal). This article is licensed under a Creative Commons Attribution 4.0 International License (CC BY).

\section{Introduction}

Evidence that corruption is detrimental to human wellbeing and economic growth is robust both in highand low-income countries (Hessami, 2014). Empirical research on corruption has too often neglected that its social cost can vary substantially depending on its 'industrial organization' (Shleifer \& Vishny, 1993), in other words, the same level of corruption may imply different corruption costs (Blackburn \& Forgues-Puccio, 2009). For example, if firms compete on cost including bribes, the positive impact of competition on productivity would remain. If firms are excluded from the market and corrupt firms do not need to compete, social costs will compound over time (Aidt, 2016).

This difference becomes more salient when considering more recent framings of corruption as favoritism and the exclusion of groups in the allocation of public resources (North, Wallis, \& Weingast, 2009). Rather than considering corruption as a transactional tax, this perspective indicates how politics may shape procurement market structure through corruption. It emphasizes that corruption is shaped by institutions and political contestation (Mungiu-Pippidi, 2015). 
While there is an extensive academic literature on the macro impacts of corruption on issues such as budget composition (Mauro, 1998), less is known about how corruption distorts markets (Olken, 2007). The structure of procurement data, consisting of transacting buyers and suppliers, makes it possible to quantify market structure using the tools of network analysis. Recent work on corruption as a networked phenomenon has advanced our understanding of how it is organized (Jancsics, 2015; Wachs, Yasseri, Lengyel, \& Kertész, 2019). Yet few studies look at how corruption excludes political outsiders even though exclusion has become a key marker of corruption (Diwan, Keefer, \& Schiffbauer, 2016; Freund, Nucifora, \& Rijkers, 2014; Goldman, Rocholl, \& So, 2013). Crucially, relevant studies only look at the existence of personal connections and their impacts rather than studying the relationships that are implicitly missing when we talk about corruption.

This article studies the impact of corruption on the structure of public procurement markets and how government turnover disrupts corruption. Corruption is thought to be especially widespread in procurement, owing to the large sums of money involved, the complexity of contracts, and discretion it lends to officials (Baldi, Bottasso, Conti, \& Piccardo, 2016). Public procurement typically accounts for $1 / 3$ of government spending in OECD countries and up to $1 / 2$ in developing economies (Djankov, Islam, \& Saliola, 2016; OECD, 2017). It also presents a formidable set of complex legal and technical details given that it is highly regulated and many products bought are high value and technologically complex, such as highways or government IT systems. Due to the unique characteristics and project-driven nature of public procurement, it often allows public officials to shape the tenders' and contracts' details according to their own discretion.

First, we distinguish corrupt and non-corrupt contracts using proxies capturing high risk situations. For example, we track if a tender is not advertised or its specifications are tailored to exclude non-favored firms. Second, we show that such corruption risks lead to qualitatively different market structure around the buyer. Compared with buyers of low corruption risk contracts, high risk buyers have sparser local networks, indicating that they have contracting relationships with fewer firms than expected. Third, we examine the impact of a change of government on these network neighborhoods. Given our framing of corruption as a collective phenomenon, embedded in the "organizational routines and cultural norms" of institutions (Kim \& Lee, 2019), we expect the shock of political turnover to induce greater network change among 'captured' buyers - those with high risk and sparse network neighborhoods. Such buyers have significantly different contractual relationships when the government changes. This suggests electoral turnover can profoundly impact corrupt relationships. In the long run, polities which limit returns to corruption with frequent political turnover can achieve better institutions, as suggested by Milanovic, Hoff, and Horowitz (2010) in the case of post-communist transitions.

We study these questions with data from the Czech Republic and Hungary. We collect contract-level administrative data from government portals and develop indicators of corruption risk. These two countries from Central and Eastern Europe (CEE) represent similar typical cases given their very comparable levels of development (Seawright \& Gerring, 2008). Their procurement systems are similar due to the overarching EU framework. Prior cross-country research on corruption and state capture generally grouped the two countries together, for example as competitive clientelistic regimes, considering them as typical cases (Fazekas \& Tóth, 2016; MungiuPippidi, 2015).

\section{Theory}

Much of the earlier scholarship on corruption has predominantly understood it as bribery, as a type of informal tax on economic transactions when companies interact with bureaucrats (Knack, Biletska, \& Kacker, 2017). It emphasizes the importance of bureaucratic meritocracy and discretion on quality of governance outcomes (Dahlström, Lapuente, \& Teorell, 2012). While this perspective on corruption certainly has its merits, it is less applicable to contexts of institutionalized corruption (Rose-Ackerman, 2015). An emerging literature defines corruption in terms of access to power and public resources and the impartiality of exercising public authority (Mungiu-Pippidi, 2015; North et al., 2009; Rothstein \& Teorell, 2008). Applying this to procurement, we define corruption in public procurement as the allocation and performance of government contracts in violation of prior explicit rules and principles of open and fair public procurement to benefit a closed network while denying access to others (Fazekas, Tóth, \& King, 2016).

We draw on theory understanding competitive clientelistic regimes as a sub-type of limited access orders, which determines the type and prevalence of corruption throughout society (Mungiu-Pippidi, 2015). In competitive clientelistic regimes such as the Czech Republic and Hungary, electoral winners take control of the state to extract rents. The group in control benefits connected firms through government contracts, regulation, privatization, access to state-backed loans, etc. This creates a partisan form of corruption by which elite groups compete for control and enrich their allies (David-Barrett \& Fazekas, 2019). Even though corruption is widespread in such countries, there is a strong variation in the level of corruption within them (e.g., by region or sector; Charron, Dijkstra, \& Lapuente, 2015). Such a setting fundamentally influences elite time horizons and the incentives to expropriate rents with corruption increasing in the likelihood of losing office (Wright, 2008).

Understanding corruption in competitive clientelistic regimes as exclusion, reflecting the power of the captor group able to dominate public procurement in 
buyer organizations, gives rise to novel empirical predictions about the impact of corruption. Corruption is a market organising force which determines contractual relationships, their distribution, and which actors have access. A dominant corrupt coalition in public procurement will tilt market forces to increase the market share of companies linked to the coalition. The magnitude of this effect depends on the strengths of corruption controls such as audit institutions or courts (David-Barrett \& Fazekas, 2019) and the degree of partisanship in the economy (Stark \& Vedres, 2012). Partisan favoritism in public procurement stands in contrast with a system of pervasive corruption whereby large companies corrupt all major parties to guarantee their continued access to government contracts (a phenomenon we cannot explicitly model in our empirical design). Corrupt misallocation of contracts harms economic efficiency by weakening competition and the incentives to deliver on contract (Coviello \& Mariniello, 2014). Understanding corruption as an organising force in public procurement markets at the level of buyers, we put forward two hypotheses:

$\mathrm{H} 1$ : Higher corruption leads to uneven distribution of spending among suppliers on the market.

$\mathrm{H} 2$ : Higher corruption leads to stronger exclusion of non-favored suppliers.

The theory of competitive clientelistic or particularistic regimes also suggests when the distribution of power changes, for example following a change in government, the fortunes of favored suppliers should change more than that of their less-favored rivals. If success depends on proximity to political power, then changes in the distribution of that power ought to be reflected in the market (Goldman et al., 2013; Mungiu-Pippidi, 2015). If government accountability is effectively pursued through elections, then we should expect government turnover to weaken the link between corruption on network structure (Eggers, 2014). However, if electoral accountability is ineffective, government change would only replace the captors but leave the biased structure of procurement markets unaltered (Fazekas \& Tóth, 2016). Given the high degree of partisanship in Hungary and to a lesser degree in the Czech Republic, we hypothesize that:

H3: Government turnover temporarily mutes the effect of corruption on the exclusion of non-favored suppliers (competitive clustering).

\section{Data and Measures}

\subsection{Data Used}

The government contracting data studied in this article were collected from the official government public procurement portals using automated web scrapers and parsing algorithms extracting key fields from semi- structured HTML code. All contracts regulated by national public procurement laws must be reported on these portals if their value is above official thresholds. Besides contracts below thresholds, certain contracts may be missing such as top-secret defense contracts. By implication, our contracting data provide a close to complete picture of what governments, state owned enterprises, and semi-public bodies financed by the state buy to the value of 3-7\% of annual GDP. They are also very diverse, encompassing contracts in markets such as office supplies, specialized legal services, road construction, or electricity. We collected all contracts in Hungary from 2009 to 2014, and in the Czech Republic from 2006 to 2013. The time series are partially non-overlapping and do not extend to the present because of changes in reporting formats, representing the maximally comparable contract-level databases available for these two countries; for more details see the supplementary file.

From each contract, we extract the buyer (the issuer of the contract) and supplier (the firm), the number of bids submitted, the date of award, the contract value (which we transform to Euros and adjust for inflation), and several further buyer, supplier, and contractlevel variables used for calculating the Corruption Risk Index (CRI).

\subsection{Government Contracting Markets as Networks}

Networks have been used to study a wide variety of phenomena from the natural and social sciences (Albert \& Barabási, 2002). We represent public procurement markets as bipartite networks. When a buyer and a supplier have a contracting relationship, we connect them by an edge. The edge carries the total contract value, the count of contracts, and the average corruption risk of contracts between the buyer and supplier. Bipartite networks refer to networks with two distinct classes of nodes (in our cases buyers and suppliers) among which there can be no edges. We visualize a toy example network in Figure 1.

In the case of public contracting, this approach is relatively new. Fazekas and Tóth (2016) established that high corruption risk organizations are clustered in procurement markets viewed as networks, indicating the presence of state capture, and that global network measures of the market reflect centralizing trends in the bureaucracy. Fierăscu (2017) expands on this approach and relates local network configurations to corruption risk across several years of Hungarian procurement. This perspective is perhaps closest to our own, as we also seek to relate local network information with corruption. More generally, criminologists have long observed that illicit behavior leaves distinct behavior traces in relational data (Papachristos, 2011) and that networks can provide substantial insight on the organization of criminal gangs (Calderoni, Brunetto, \& Piccardi, 2017), high level political corruption (Luna-Pla \& Nicolas-Carlock, 2020), and cartels (Wachs \& Kertész, 2019). 


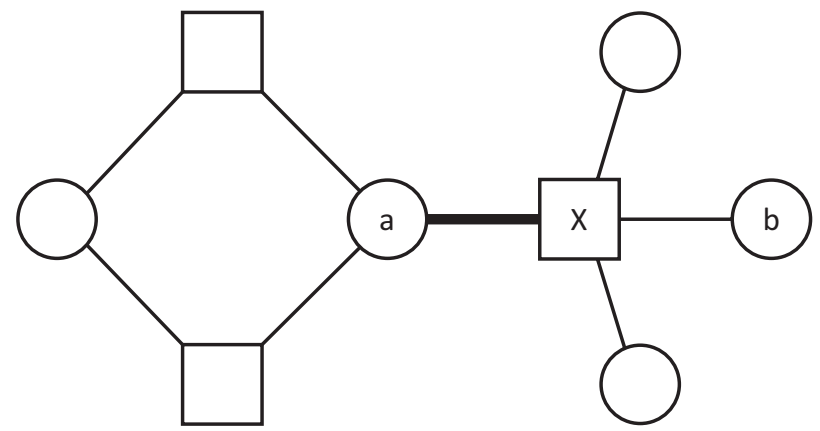

Figure 1. A network representation of an artificial toy public contracting market. Notes: The squares represent buyers and the circles suppliers. A buyer and supplier are connected by an edge if they have a contracting relationship. The width of the edge increases as the value of the contracts between the buyer and supplier increases. For example, suppliers a and $b$ are both connected to buyer $X$, indicating that they have won at least one contract from $X$. Supplier a has won substantially more contract value from buyer $X$, indicated by the thickness of the edge connecting the two.

In Figure 2, we visualize the 2009 Czech and Hungarian public procurement markets as networks. We show only the nodes and edges connected to the largest component of the graph. The disconnected nodes are less than $10 \%$ of the network in both cases. We note that even though we consider the entire market, including contracts for hospital beds, road repair, and school lunches, the networks are densely connected. The path length from one randomly chosen node to another is only six on average.

\subsection{Measuring Corruption Risks Objectively: The Main Independent Variable}

Micro-level objective indicators of corruption in public contracting are a recent development (Fazekas et al., 2016). The online reporting of public procurement contracts in several countries makes it possible to score con- tracts for corruption risk en masse. We use an established method of measuring corruption risk called the $\mathrm{CRI}$, which checks for certain red flags in contract metadata known from case studies to be linked to corruption (Pricewaterhouse Coopers, 2013; World Bank, 2009). The $C R I$ is an aggregate measure counting the presence of these red flags as measured by elementary corruption risk indicators (Fazekas \& Kocsis, 2020). CRI measures corruption risks only in competitive markets, that is, markets where competition would be expected in the absence of corruption. In practice, this means that markets where there are only few different suppliers (less than three) in the historical records are excluded from the analysis.

The elementary corruption risk indicators fall into three groups: those describing red flags in the submission phase; the assessment of bids phase; and the outcome phase (Table 1). During the submission phase, companies may be blocked from participation if the call was
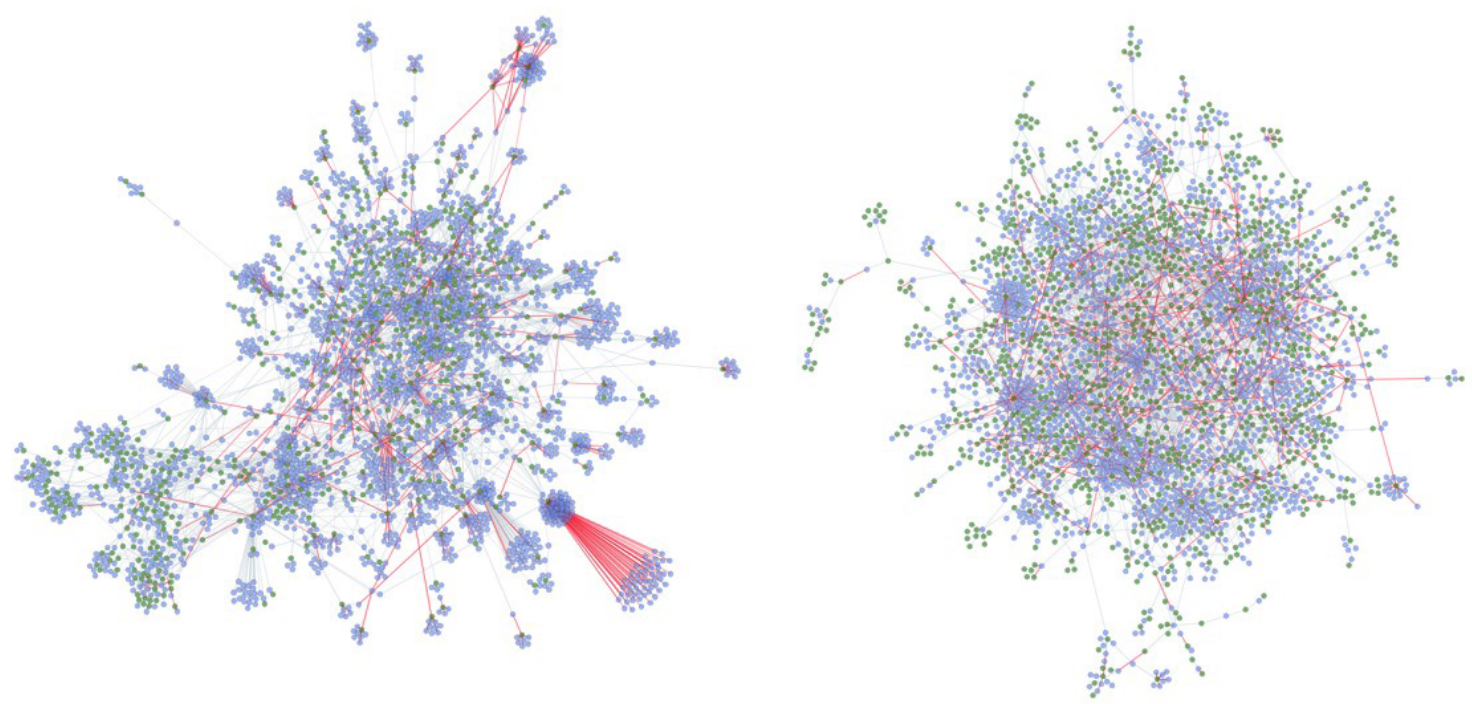

Figure 2. Hungarian and Czech procurement markets in 2009. Notes: Green nodes are buyers, purple nodes are suppliers. Edges are colored red if the average CRI of contracts between the buyer and supplier in question are at least one standard deviation above the market average. 
Table 1. Contract-level indicators of corruption risk.

\begin{tabular}{|c|c|c|}
\hline Procedure phase & Indicator name & Indicator values \\
\hline \multirow[t]{5}{*}{ Submission } & Call for tender not published & $\begin{array}{l}0=\text { Call for tender published in official journal } \\
1=\text { No call for tenders published in official journal }\end{array}$ \\
\hline & Procedure type & $\begin{array}{l}0=\text { Open procedure } \\
1=\text { Non-open procedure (e.g., invitation tender) }\end{array}$ \\
\hline & Length of eligibility criteria & Number of characters of the eligibility relative to market average \\
\hline & Length of advertisement period & $\begin{array}{l}\text { Number of days between publication of call for tenders and } \\
\text { submission deadline }\end{array}$ \\
\hline & Call for tenders modification & $\begin{array}{l}0=\text { Call for tenders not modified } \\
1=\text { Call for tenders modified }\end{array}$ \\
\hline \multirow[t]{2}{*}{ Assessment } & $\begin{array}{l}\text { Weight of non-price evaluation } \\
\text { criteria }\end{array}$ & $\begin{array}{l}\text { Sum of weights for evaluation criteria which are not related to } \\
\text { prices or quantities }\end{array}$ \\
\hline & Length of decision period & $\begin{array}{l}\text { Number of working days between submission deadline and award } \\
\text { announcement }\end{array}$ \\
\hline Outcome & Single bidder contract & $\begin{array}{l}0=\text { More than one valid bid received } \\
1=\text { One bid received }\end{array}$ \\
\hline
\end{tabular}

not published in the official journal, modified during the submission period, if the procedure type was not open, if eligibility criteria were over-determined, or if deadline was short. Non-favored companies may still be barred from winning a tender in the assessment phase. Nonprice or quantity criteria in the evaluation of bids give the decision-maker discretion and limits accountability. If the time it takes the buyer of the tender to decide on the winner is short, it may indicate a premediated choice. Finally, a single-bidder outcome in a competitive market is a strong indicator that the tender lacked competition.

The composite CRI is the arithmetic average of the scaled elementary indicators, all falling in the 0-1 range. Though certainly not an exhaustive index of corruption strategies, it represents a varied collection of simple strategies used in practice by corrupt actors.

The CRI has been shown to be significantly related to both macro and micro measures of corruption (Charron, Dahlström, Fazekas, \& Lapuente, 2017). At the EU regional-level, average CRI has a strong negative correlation with the European Quality of Government Index (EQI, $\rho \sim-.54$ ), and a strong positive correlation with the two subcomponents of the EQI directly measuring corruption risk: corruption perception $(\rho \sim .47)$ and reported bribery $(\rho \sim$.59). At the contract-level, high-CRI contracts have been shown to predict higher prices relative to cost estimates across the EU. The CRI of contracts awarded by buyers across Europe to companies registered in tax havens is higher (Fazekas \& Kocsis, 2020).

\subsection{Measuring Contracting Network Structure: Dependent Variables}

We define three buyer-level measures describing market structure: entropy, unweighted competitive clustering, and weighted competitive clustering. To measure change over time we define buyer persistence.

Entropy: For a buyer $i, p_{i}(j)$ denotes the fraction of $i$ 's contract value awarded to supplier $j$. We calculate the normed entropy of a buyer's distribution as:

$$
H(i)=-\frac{\sum_{j \in J} p_{i}(j) \times \log \left(p_{i}(j)\right)}{\log (|J|)}
$$

The normed entropy of a uniform distribution equals 1 . Entropy tends to 0 as the distribution becomes more heterogeneous.

Unweighted competitive clustering: One important local network measure is the clustering coefficient. In most empirical networks, the number of connected triangles is much larger than would be expected than if the nodes were connected at random. In social networks this phenomenon is often summarized as 'a friend of my friend is my friend.' The classical clustering coefficient of a node can be interpreted as a probability: given two friends of the node, what is the likelihood that they are friends too?

Bipartite networks do not contain triangles. Instead, we consider local clustering in terms of squares. Given the focal buyer $i$, we expect that those suppliers who win from buyers near to $i$ to be much more likely to win from $i$ than suppliers more distant in the network. In a market without favoritism, we are more likely to observe a closure phenomenon, as we do in social networks, in which buyers contract with suppliers adjacent to their neighboring institutions much more frequently than at random. All other things being equal, buyers who contract with the same suppliers have some similarity.

We visualize this probability as the dotted line edge in Figure 3. In the context of public procurement markets, we call this probability competitive clustering. 
Qualitatively, we expect an edge between a buyer (B) and a supplier (S) to be more likely if the supplier (S) competes with other suppliers $\left(S^{\prime}\right)$ which serve the buyer (B), at other buyers $\left(\mathrm{B}^{\prime}\right)$. We argue that sharing a supplier implies that the two buyers have some similarity, be it in terms of geography, technology, or scale, and that this similarity will manifest in the sharing of other suppliers.

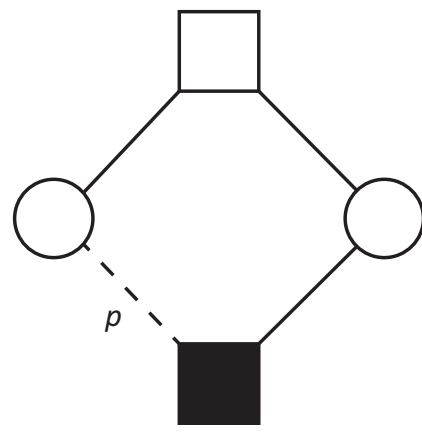

Figure 3. Competitive clustering. Notes: Unweighted competitive clustering of the focal buyer, visualized as a black square, is defined as the probability of the dashed edge existing given all other edges in the graph. A second buyer, the white square, and the focal buyer both contract with the supplier on the right. This similarity between the two buyers suggests that if the white buyer also contracts with the buyer on the left, then the focal buyer is much more likely to also contract with that buyer.

Mathematically, we define the competitive clustering of a buyer as the number of four-step paths, $C_{i}(4)$, starting and ending at that buyer, divided by the paths of length three, $P_{i}(3)$, starting at the buyer:

$$
C C_{i}=\frac{C_{i}(4)}{P_{i}(3)}
$$

This is a local version of the measure introduced by Robins and Alexander (2004). It is related to the square clustering measure of Lind, Gonzalez, and Herrmann
(2005), which calculates the probability of observing edges between neighbors and second order neighbors of the focal node. It can also be contrasted with Opsahl's (2013) clustering measure. In Figure 4, we calculate two examples of the competitive clustering around a hypothetical buyer.

Weighted competitive clustering: As edge weights, encoding the total contract value and hence the strength of a contracting relationship between a supplier and a buyer, play an important role in our networks, we propose a second measure extending competitive clustering to incorporate edge weights. The measure should equal 1 for a buyer if its competitive clustering is 1 and the weights on all edges are homogeneous. We again compare the ratio of four-cycles to three-paths. We multiply each path of length four by the geometric mean of its scaled edge weights: This quantity is maximized if the edge weights are identical. As the weights tend to unity, the measure converges to the unweighted competitive clustering measure. Mathematically, count each four-cycle centered at the focal buyer i weighted by the geometric mean of the scaled weights in the cycle:

$$
C C_{i}=\frac{C_{i}(4)}{P_{i}(3)} \times \sum_{j, k, l \in C_{i}}\left(w_{i j} w_{j k} w_{k l} w_{i l}\right)^{1 / 4}
$$

As contract values have great heterogeneity both across the network and locally, we scale the weights dynamically for each buyer by dividing by the maximum edge weight in its 3-node neighborhood.

Persistence: We define buyer network change over time by measuring the correlation of its contract award profile across years. Specifically, we consider all suppliers winning contracts from the buyer in either year $A$ or $B$ or both, and create two vectors: one encoding the distribution of contract value in year $A$, the other the same for year $B$. We call the Pearson-correlation of these two vectors the (A, B)-persistence (Nicosia et al., 2013) of a buyer. (A, B)-persistence of a buyer is 1 if the buyer's contract awards are distributed with the same relative contract values to the same suppliers in years $A$ and $B$.
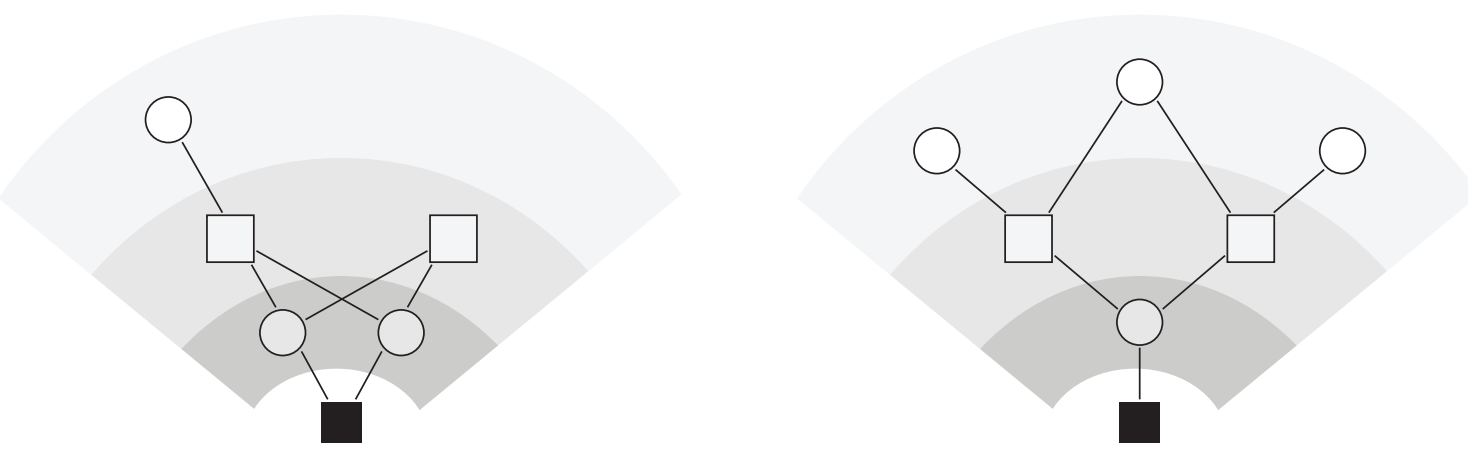

Figure 4. The competitive clustering of two focal buyers. Notes: The first buyer has a dense local network-there are many paths of length four starting and ending at the focal buyer. Hence, the first buyer has a high competitive clustering of $4 / 6=2 / 3$. The second buyer has a sparse local network and a competitive clustering of 0 : no path of length four starting from the black buyer that returns to that buyer. 
(A, B)-persistence can attain a minimal value of -1 in the case that the issuance of a buyer goes to a completely different set of suppliers in year A compared to year B.

\section{Methods}

\subsection{Case Selection}

Hungary and the Czech Republic represent comparable, typical cases given their very similar levels of development, prevalence of corruption, regulatory framework, and government turnovers (Seawright \& Gerring, 2008). Both countries have GDP per capita slowly converging to the EU average (reaching between $65-75 \%$ by the early 2010s). They also score close to the average of the Corruption Perception Index for CEE EU member states (53.25 in 2013) with scores 48 and 54 respectively on a scale between 0 (corrupt) and 100 (clean; Transparency International, 2013). Objective corruption proxies in public procurement such as share of single bidder tenders on competitive markets are very similar: $24 \%$ and $28 \%$ of contracts received a single bid in the Czech Republic and Hungary, respectively in 2009-2014 (Fazekas \& Kocsis, 2020). Prior research on corruption and state capture generally grouped the two countries together. For instance, both are considered competitive clientelistic regimes in which political winners use their office to reward cronies by redistributing public resources (Mungiu-Pippidi, 2015). Despite these similarities, the countries have diverged recently. Hungary's institutional quality and corruption level have deteriorated since 2010 (Bánkuti, Halmai, \& Scheppele, 2012), while the Czech Republic has remained stable, broadly speaking. Public procurement regulatory and administrative systems are very similar in the two countries given the overarching EU framework of the Public Procurement Directives, similarities in national legislation outside of the Directives, and largely identical administrative systems including electronic procurement portals. Both countries experienced considerable government turnovers in our observation period, with larger swings between parties in Hungary than in the Czech Republic.

\subsection{Empirical Models and Identification}

To formally test our hypotheses, we employ three scaled dependent variables at the buyer/year level: i) entropy which (H1); ii) competitive closure (H2); and iii) weighted competitive clustering ( $\mathrm{H} 1$ and $\mathrm{H} 2)$. For each country and each dependent variable, we run two regression models: a pooled OLS model and a buyer fixed-effects panel model. We consider only those buyers with at least five contracts in our data set to exclude the smaller organizations whose behavior is noisier. We find similar results, documented in Appendix $A$ in the Supplementary File, when we restrict to buyers with at least 10 contracts. In both cases, the dependent variables are calculated on the full networks.
The panel data equation we estimated is:

$$
y_{i, t}=\beta_{1} \times C R I_{i, t}+\beta_{2} X_{i, t}+\alpha_{i}+e_{i, t}
$$

Where $y_{i, t}$ is the dependent variable observed for buyer $i$ at time $t, C R I_{i, t}$ is our main independent variable, the measure of corruption risks, $X_{i, t}$ is the matrix of control variables, $\alpha_{i}$ is the time-invariant individual buyer effect, and $e_{i, t}$ is the error term. The matrix of control variables contained the following indicators:

- The log of number of contracts awarded by the buyer in that year;

- The log of the total value of contracts awarded by the buyer in that year;

- An election year dummy: 1 if the year in question had a parliamentary election in that country results in a change in government;

- The interaction of $\mathrm{CRI}$ and the election year dummy;

- Year dummies;

- Buyer type, distinguishing between local and central government institutions, provided by the public procurement registry (only in pooled OLS);

- Buyer location, based on the NUTS-II classification (only in pooled OLS);

- Buyer sector (Hungary-only), describing the primary sector of the buyer, provided by the public procurement registry (only in pooled OLS).

In the absence of an experimental setting, the buyerlevel fixed effects panel data models provide a reliable and valid estimate of the hypothesized causal effects for several reasons. First, they control for unobserved organizational characteristics such as spending preferences influencing supplier composition (e.g., taste for high quality goods). Second, year dummies control for common shocks occurring over time separately in each of the countries. Third, indicators of time varying organizational characteristics such as total value and number of contracts awarded and sectoral composition of spending control of obvious confounding factors simultaneously determining market structure as well as corruption risks. Fourth, our analysis is based on the full sample of government contracting activities barring few specific spending lines such as defense contracts with national security implications. This means that sampling bias poses little threat to identification, a challenge which often limits the generalizability of experimental and quasiexperimental designs. Fifth, the corruption and network measures are constructed from different micro variables on different measurement levels minimizing the risk of double-counting the same phenomena on both sides of the equation. We only consider contracts awarded on competitive markets, defined as having at least three active suppliers (e.g., monopolistic markets determined by technology do not bias results).

Our regressions are run using the plm package of the R programming language (Croissant \& Millo, 2008). 
To account for possible cross-sectional correlation in the errors, we report panel-corrected standard errors, following Beck and Katz (1995). As a check against the potential non-independence of observations in the contracting network, we simulate $p$-values using Monte Carlo random permutations; see Appendix $B$ in the Supplementary File (Good, 2006). Finally, in Appendix C in the Supplementary File we show the results of the competitive clustering models with year fixed-effects included to control for temporal shocks.

\section{Results}

\subsection{Uneven Spending Distribution: Entropy}

With regards to $\mathrm{H} 1$, we find limited evidence that $\mathrm{CRI}$ impacts buyer entropy in either country, shown in Table 2. Though both pooled OLS models show a statistically significant negative effect of CRI on entropy as expected, the more reliable fixed-effects panel data models do not support this conclusion.

The lack of clear support for $\mathrm{H} 1$ is perhaps not surprising, given, for example, the recent research on politicaleconomic networks in Hungary suggesting that missing business connections are driving market outcomes (Stark \& Vedres, 2012). Our dependent variable in these models is entropy amongst the winners of the buyer's awarded contracts, which is a biased measure of corruption as it neglects those suppliers which have been totally ex- cluded from the market. This bias increases as total exclusion becomes the dominant effect of corruption. Hence, we now check models in which the dependent variable explicitly quantifies exclusion.

\subsection{Excluding Non-Favored Suppliers: Competitive Clustering}

This analysis, summarized in Table 3, leads to three notable insights. First, with regards to $\mathrm{H} 2$, our regression models provide clear support for our hypothesized empirical relationship. In both countries, both model specifications show a significant negative relationship between $\mathrm{CRI}$ and competitive clustering. This means that corruption in both countries leads to exclusion in buyers' local markets. Contrasted with the finding that entropy and CRI are unrelated, this relationship indicates that corruption in these countries manifests as missing local connections in contracting networks. Such interpretation bodes well with macro-institutional accounts of competitive clientelistic regimes.

Second, we also find that in all models, effect sizes are larger in Hungary than in the Czech Republic: The impact of corruption on market structure is roughly 1.5-2 times larger in Hungary. Note that all variables are standardized.

Third, the interaction term between CRI and the election year dummy is not significant in either model, indicating that the there is no difference in the relationship

Table 2. Pooled OLS and buyer fixed-effects regression models predicting buyer entropy.

\begin{tabular}{|c|c|c|c|c|}
\hline & \multicolumn{4}{|c|}{ Dependent variable: Buyer entropy, $\geq 5$ contracts } \\
\hline & \multicolumn{2}{|c|}{ Hungary } & \multicolumn{2}{|c|}{ Czech Republic } \\
\hline & (1) & $(2)$ & (3) & (4) \\
\hline \multirow[t]{2}{*}{$\overline{\mathrm{CRI}}$} & $-.009^{\circ}$ & .002 & $-.014 *$ & -.004 \\
\hline & $(.005)$ & $(.005)$ & $(.006)$ & $(.006)$ \\
\hline \multirow[t]{2}{*}{ Election year dummy } & $-.038 * * *$ & -.016 & -.012 & -.005 \\
\hline & $(.011)$ & $(.010)$ & $(.011)$ & $(.010)$ \\
\hline \multirow[t]{2}{*}{ Buyer number of contracts (log) } & $.044 * * *$ & $.077 * * *$ & $.044 * * *$ & $.057 * * *$ \\
\hline & $(.006)$ & $(.007)$ & $(.005)$ & $(.006)$ \\
\hline \multirow[t]{2}{*}{ Buyer contract value (log) } & $-.053 * * *$ & $-.103 * * *$ & $-.045 * * *$ & $-.096 * * *$ \\
\hline & $(.003)$ & $(.004)$ & $(.003)$ & $(.004)$ \\
\hline \multirow[t]{2}{*}{ CRI, election year interaction } & $-.029 * *$ & $-.018^{\circ}$ & -.016 & -.022 \\
\hline & $(.010)$ & $(.011)$ & $(0.16)$ & $(.015)$ \\
\hline \multirow[t]{2}{*}{ Constant } & $1.285 * * *$ & & $1.222 * * *$ & \\
\hline & $(.045)$ & & $(.043)$ & \\
\hline Model & Pooled OLS & $\begin{array}{l}\text { Buyer, year } \\
\text { Fixed Effects }\end{array}$ & Pooled OLS & $\begin{array}{l}\text { Buyer, year } \\
\text { Fixed Effects }\end{array}$ \\
\hline Type, location, sector ${ }^{+}$dummies & Yes & - & Yes & - \\
\hline Observations & 3,657 & 3,657 & 2,704 & 2,704 \\
\hline $\mathrm{R}^{2}$ & .145 & .248 & .115 & .209 \\
\hline \multirow[t]{2}{*}{ F statistic } & $20.448 * * *$ & $121.052 * * *$ & $18.312 * * *$ & $95.737 * * *$ \\
\hline & $\begin{array}{l}\text { (degrees of freedom } \\
[\mathrm{df}]=30 ; 3626)\end{array}$ & $(d f=5 ; 1838)$ & $(\mathrm{df}=19 ; 2684)$ & $(\mathrm{df}=5 ; 1813)$ \\
\hline
\end{tabular}

Notes: We report panel-corrected standard errors. ${ }^{\circ} \mathrm{p}<.1,{ }^{*} \mathrm{p}<.05,{ }^{* *} \mathrm{p}<.01,{ }^{* * *} \mathrm{p}<.001 ;^{+}$sector only available for Hungary. 
Table 3. Pooled OLS and buyer fixed-effects regression models predicting buyer competitive clustering.

\begin{tabular}{|c|c|c|c|c|}
\hline & \multicolumn{4}{|c|}{ Dependent variable: Buyer competitive clustering, $\geq 5$ contracts } \\
\hline & \multicolumn{2}{|c|}{ Hungary } & \multicolumn{2}{|c|}{ Czech Republic } \\
\hline & (1) & $(2)$ & (3) & (4) \\
\hline CRI & $\begin{array}{l}-.072 * * * \\
(.005)\end{array}$ & $\begin{array}{l}-.046 * * * \\
(.005)\end{array}$ & $\begin{array}{l}-.024 * * * \\
(.006)\end{array}$ & $\begin{array}{l}-.029 * * * \\
(.006)\end{array}$ \\
\hline Election year dummy & $\begin{array}{l}-.023 * \\
(.011)\end{array}$ & $\begin{array}{l}.031 * * \\
(.010)\end{array}$ & $\begin{array}{l}-.013 \\
(.010)\end{array}$ & $\begin{array}{l}-.028 * * \\
(.009)\end{array}$ \\
\hline Buyer number of contracts (log) & $\begin{array}{l}.137^{* * *} \\
(.011)\end{array}$ & $\begin{array}{l}.102 * * * \\
(.007)\end{array}$ & $\begin{array}{l}.158 * * * \\
(.006)\end{array}$ & $\begin{array}{l}.148 * * * \\
(.006)\end{array}$ \\
\hline Buyer contract value (log) & $\begin{array}{c}-.015^{* * *} \\
(.003)\end{array}$ & $\begin{array}{c}.002 \\
(.004)\end{array}$ & $\begin{array}{c}.003 \\
(.003)\end{array}$ & $\begin{array}{l}.004 \\
(.004)\end{array}$ \\
\hline CRI, election year interaction & $\begin{array}{c}-.021 * \\
(.010)\end{array}$ & $\begin{array}{c}-.002 \\
(.010)\end{array}$ & $\begin{array}{r}.007 \\
(0.14)\end{array}$ & $\begin{array}{l}.005 \\
(.014)\end{array}$ \\
\hline Constant & $\begin{array}{c}.029 \\
(.050) \\
\end{array}$ & & $\begin{array}{l}-.137^{* * *} \\
(.047)\end{array}$ & \\
\hline Model & Pooled OLS & Buyer, year FE & Pooled OLS & Buyer, year FE \\
\hline Type, location, sector ${ }^{+}$dummies & Yes & - & Yes & - \\
\hline Observations & 3,657 & 3,657 & 2,704 & 2,704 \\
\hline $\mathrm{R}^{2}$ & .424 & .192 & .463 & .306 \\
\hline F statistic & $\begin{array}{c}99.934 * * * \\
(\mathrm{df}=30 ; 3626)\end{array}$ & $\begin{array}{c}87.276 * * * \\
(\mathrm{df}=5 ; 1838)\end{array}$ & $\begin{array}{c}121.604 * * * \\
(\mathrm{df}=19 ; 2684)\end{array}$ & $\begin{array}{r}159.898 * * * \\
(d f=5 ; 1813)\end{array}$ \\
\hline
\end{tabular}

Notes: We report panel-corrected standard errors. ${ }^{\circ} \mathrm{p}<.1,{ }^{*} \mathrm{p}<.05,{ }^{* *} \mathrm{p}<.01,{ }^{* * *} \mathrm{p}<.001$; $^{+}$sector only available for Hungary.

between corruption risk and competitive clustering during years that see a change in government compared to those without. This indicates that, if changes in government result in a significant change in buyer behavior, it is not observable within the same year of the change in government. This test does not lend support to H3.

To further bridge the different degrees of market structure reconfiguration resulting from corruption, that is, explore the overlaps between $\mathrm{H} 1$ and $\mathrm{H} 2$, we also consider weighted competitive clustering as an outcome variable. Weighted competitive clustering measures both the exclusion and heterogeneity in the observed contract value distributions, hence aims to reflect both $\mathrm{H} 1$ and $\mathrm{H} 2$. We find results similar to the unweighted competitive clustering case across all four models (Table 4), suggesting that the unweighted competitive clustering results are robust to edge weight heterogeneity.

Despite the insignificant relationship between CRI and entropy, the significant relationship between CRI and weighted competitive clustering lends some support to $\mathrm{H} 1$. We posit that in markets where non-favored suppliers command unique skills and capacities, their total exclusion would be counterproductive even if total exclusion is typically the norm. Practically, a tender tailored to a specific supplier may be won by an outsider. The red flags of the CRI are strategies of corrupt contract allocation; they do not secure the tender for favored suppliers.

How can we relate this to a concrete market outcome? A one standard deviation increase in CRI is approximately the same as having one more red flag, on aver- age. In the Hungarian case, this means that if a buyer has one more red flag on average, its competitive clustering will be half a standard deviation lower. Ceteris paribus, a one standard deviation decrease in competitive clustering means having three fewer suppliers. In Hungary, an additional red flag on average means that a buyer contracts with 1.5 fewer suppliers in a given year. The same analysis in the Czech Republic indicates that an additional red flag on average means around 1 fewer supplier per year. The average buyer in each country has around 10 suppliers per year. In other words, an additional red flag means roughly a $10-15 \%$ decrease in the number of suppliers a buyer contracts with.

\subsection{Government Change: Captured Buyers and Persistence}

Having established the link between CRI and the topology of a buyer's network neighborhood via competitive clustering, we now return to $\mathrm{H} 3$ by checking the impact of government change using issuer persistence as dependent variable. We define buyers as captured if they have above average CRI and below average competitive clustering in a year and non-captured otherwise. Contrasting captured and non-captured buyers' persistence throughout periods of government change directly tests H3. When governments change and bureaucrats are replaced, we expect captured buyers to have less persistent issuance.

We continue to use an annual time frame and consider changes in buyer behavior across years. We analyze 
Table 4. Pooled OLS and buyer fixed-effects regression models predicting buyer weighted competitive clustering.

\begin{tabular}{|c|c|c|c|c|}
\hline & \multicolumn{4}{|c|}{ Dependent variable: Buyer weighted competitive clustering, $\geq 5$ contracts } \\
\hline & \multicolumn{2}{|c|}{ Hungary } & \multicolumn{2}{|c|}{ Czech Republic } \\
\hline & (1) & $(2)$ & (3) & (4) \\
\hline CRI & $\begin{array}{c}-.064 * * * \\
(.005)\end{array}$ & $\begin{array}{c}-.047^{* * *} \\
(.005)\end{array}$ & $\begin{array}{c}-.012 * \\
(.006)\end{array}$ & $\begin{array}{c}-.014 * \\
(.006)\end{array}$ \\
\hline Election year dummy & $\begin{array}{l}.016 \\
(.011)\end{array}$ & $\begin{array}{l}.020^{\circ} \\
(.010)\end{array}$ & $\begin{array}{l}.020^{\circ} \\
(.010)\end{array}$ & $\begin{array}{l}.005 \\
(.010)\end{array}$ \\
\hline Buyer number of contracts (log) & $\begin{array}{l}.094^{* * *} \\
(.006)\end{array}$ & $\begin{array}{l}.070 * * * \\
(.007)\end{array}$ & $\begin{array}{l}.090 * * * \\
(.005)\end{array}$ & $\begin{array}{l}.080 * * * \\
(.006)\end{array}$ \\
\hline Buyer contract value (log) & $\begin{array}{l}-.003 \\
(.003)\end{array}$ & $\begin{array}{l}.010 * \\
(.004)\end{array}$ & $\begin{array}{l}.017^{* * *} \\
(.003)\end{array}$ & $\begin{array}{l}.021^{* * *} \\
(.004)\end{array}$ \\
\hline $\mathrm{CRI}$, election year interaction & $\begin{array}{l}.001 \\
(.010)\end{array}$ & $\begin{array}{l}.015 \\
(.011)\end{array}$ & $\begin{array}{l}-.005 \\
(0.15)\end{array}$ & $\begin{array}{c}-.015 \\
(.014)\end{array}$ \\
\hline Constant & $\begin{array}{l}-.035 \\
(.046)\end{array}$ & & $\begin{array}{l}-.207 * * * \\
(.044)\end{array}$ & \\
\hline Model & Pooled OLS & Buyer FE & Pooled OLS & Buyer FE \\
\hline Type, location, sector ${ }^{+}$dummies & Yes & - & Yes & - \\
\hline Observations & 3,657 & 3,657 & 2,704 & 2,704 \\
\hline $\mathrm{R}^{2}$ & .315 & .114 & .300 & .142 \\
\hline F statistic & $\begin{array}{c}55.585 * * * \\
(\mathrm{df}=30 ; 3626)\end{array}$ & $\begin{array}{c}47.269 * * * \\
(\mathrm{df}=5 ; 1838)\end{array}$ & $\begin{array}{c}60.461 * * * \\
(\mathrm{df}=19 ; 2684)\end{array}$ & $\begin{array}{c}59.970 * * * \\
(\mathrm{df}=5 ; 1813)\end{array}$ \\
\hline
\end{tabular}

Notes: We report panel-corrected standard errors. ${ }^{\circ} \mathrm{p}<.1,{ }^{*} \mathrm{p}<.05,{ }^{* *} \mathrm{p}<.01,{ }^{* * *} \mathrm{p}<.001$; $^{+}$sector only available for Hungary.

pairs that are two years apart to capture the effect of a change in government in the intermediate year. For example, we are interested in the $(2009,2011)$-persistence of Hungarian buyers, as 2010 saw a change in government. Hence, we will refer to two-year difference persistence simply as persistence.

To test $\mathrm{H} 3$, we investigate buyer persistence for each country in greater detail. We group captured and noncaptured buyers and plot the distributions of persistences across regular years and change of government years in Figure 5. Comparing the persistences of cap- tured vs non-captured buyers across normal and politically volatile years reveals a clear picture in line with $\mathrm{H} 3$. In both countries, the persistence of captured buyers is lower than that of non-captured buyers in periods with government change while differences in persistence are statistically indistinguishable in periods without government change. The effect in Hungary is larger than in the Czech Republic.

We verify the significance of the observed differences using a permutation test (Good, 2006). We randomly shuffle the capture category labels 1000 times and

Two Year Issuer Persistence

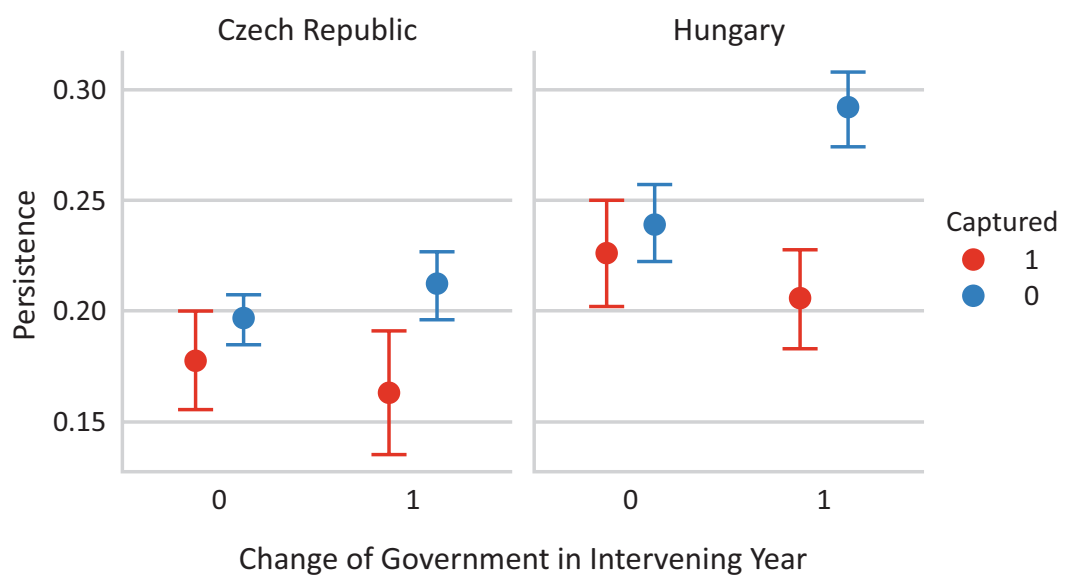

Figure 5. Comparison of persistence of captured and non-captured buyers across years with and without government change. Notes: Captured buyers are defined as those with high CRI and low competitive clustering. Persistence is defined as the correlation of the buyer's issuance of contract value to suppliers over two years (e.g., 2009 to 2011). 
recalculate the difference in persistence between captured and non-captured buyers. We calculate a $p$-value by counting the number of times the randomized captured vs non-captured persistence difference is less than the real difference, that is, we compare the observed empirical relationship to a truly random distribution of the capture label.

In Table 5, we see that captured buyers are significantly less persistent across the 2010 Hungarian change in government. They are also significantly less persistent from 2012 to 2014. The effect size of buyer capture is by far the largest from 2009 to 2011, bridging the change of government in 2010. It is also significant, albeit with a smaller effect size across the 2010-2012 period. This may indicate that it takes the corrupt elites some time capture buyer institutions, and that the rewiring of contracting networks lags turnover. Captured Hungarian buyers have $38 \%$ weaker correlation in their issuance profiles across the change in government than their noncaptured peers.

In the Czech Republic, we also see the strongest negative effect of capture on persistence in the years across the change in government in 2010: 2008-2010, 2009-2011, and 2010-2012 in line with our hypotheses. Like for Hungary, the relationship is significant for an extended period, again suggesting that the capture of institutions takes time. We also show histograms of the randomized persistences and the actual persistence for each year in Appendix $\mathrm{E}$ in the Supplementary File.

These findings support H3: Government turnover has an impact on corrupt contacting networks. They provide evidence of politically-driven state capture among public buyers in both countries and demonstrate the value of using both micro-level risk indicators and network features to relate corruption in procurement to the political cycle.

\section{Conclusion}

This article analyzes the connection between corruption and market structure in public procurement markets. We use a network framework to test qualitative hypotheses from the literature on corruption in a quantitative setting. Specifically, we find strong evidence at the microlevel that corruption in public procurement is predominantly about the exclusion of non-favored suppliers. This is in line with theories of corruption as particularism, or the preferential treatment of groups by the state. Backof-the-envelope calculations suggest that at the margin, if a buyer awards contracts with an additional red flag on average, it will contract with $10-15 \%$ fewer unique suppliers. These missing connections are the manifestation of corrupt behavior distorting market structure.

We validate the political nature of the inverse relationship between corruption and competitive clustering by observing that buyers with high CRI and low competitive clustering, which we refer to as captured, see significantly larger changes in their contracting relationships across government changes than other buyers. In Hungary, the correlation of contract awards of a captured buyer across an election year is $38 \%$ weaker than a noncaptured buyer. In the Czech Republic, this relationship is $21 \%$.

We suggest that our work has wider implications. For the literature on corruption and state capture, our findings provide empirical evidence about the mechanisms of corrupt allocation of government resources. For policymakers, our approach suggests that networks can visualize clusters of corruption risk. Simply looking at networks can reveal the structure of buyer-supplier relationships in a way that traditional statistical analysis cannot. The network framework also suggests a novel approach to corruption detection: looking for missing edges. Our article also makes the broader point that electoral contestation and power sharing can mitigate corrupt market distortions even in systematically corrupt places. Even if corruption is widespread, its power to reconfigure market relationships and impose economic costs on markets depends on political constraints. Hence, strengthening competitive democratic process can curb corruption at least its most extensive market distorting effects. Our article also suggests that corruption in

Table 5. Hungarian buyer two-year persistence permutation test: Difference between captured and non-captured buyers and significance of the difference according to a label-permuted nonparametric test of differences.

\begin{tabular}{|c|c|c|c|c|}
\hline Years & Country & Observed difference & $\%$ difference & $p$-value \\
\hline 2009, 2011 & Hungary & -0.151 & $-38 \%$ & $<.001 * * *$ \\
\hline 2010, 2012 & Hungary & -0.051 & $-14 \%$ & $.0013 * * *$ \\
\hline 2011, 2013 & Hungary & 0.014 & $+4 \%$ & .7559 \\
\hline 2012, 2014 & Hungary & -0.044 & $-12 \%$ & $.0198 * *$ \\
\hline 2006, 2008 & Czech Republic & 0.004 & $+2 \%$ & 0.57 \\
\hline 2007, 2009 & Czech Republic & -0.030 & $-11 \%$ & 0.112 \\
\hline 2008,2010 & Czech Republic & -0.045 & $-17 \%$ & $0.029 * *$ \\
\hline 2009, 2011 & Czech Republic & -0.052 & $-21 \%$ & $0.007 * * *$ \\
\hline 2010, 2012 & Czech Republic & -0.047 & $-16 \%$ & $0.020 * *$ \\
\hline 2011, 2013 & Czech Republic & 0.007 & $+2 \%$ & 0.639 \\
\hline
\end{tabular}

Note: ${ }^{* *}<.01, * *<.05, *<.10$. 
procurement can be viewed through the lens of competition policy, broadening the scope of potential anticorruption stakeholders (Luz \& Spagnolo, 2017). Finally, given the strong correlation between market distortions and government turnover, introducing contracting practices which cut across electoral cycles could weaken elected politicians' capacity to exploit public procurement for partisan gain. This could be achieved by, for example, using long mandatory guarantee clauses or multiyear service contracts spanning across electoral cycles.

We also identify several drawbacks to our approach. First, we consider only two countries from CEE which are likely not representative of the wider set of EU countries. Second, our network measure of competitive clustering is a simple measure and we posit a straightforward relationship between local network density and corruption. This problem is compounded by the fact that our data does not contain information on the individuals owning or benefiting from the suppliers. Hungarian and Czech media are full of examples of suspected corrupt oligarchs with many companies and affiliations. Third, we could not offer a direct measure of social costs of corruption arising due to market distortions. Further work could explicitly estimate market prices and social costs under scenarios of exclusionary as well as competitive corruption.

\section{Acknowledgments}

The authors would like to thank the following colleagues for helpful discussion and feedback: Toke Aidt, Zsofia Czeman, Andras Borsos, Balazs Vedres, David Deritei, Bence Toth, Carl Nordlund, and Silvia Fierăscu. We would also like to thank the anonymous reviewers whose comments greatly improved the manuscript.

\section{Conflict of Interests}

The authors declare no conflict of interests.

\section{Supplementary Material}

Supplementary material for this article is available online in the format provided by the authors (unedited).

\section{References}

Aidt, T. (2016). Rent seeking and the economics of corruption. Constitutional Political Economy, 27(2), 142-157.

Albert, R., \& Barabási, A. L. (2002). Statistical mechanics of complex networks. Reviews of Modern Physics, 74(1), 47.

Baldi, S., Bottasso, A., Conti, M., \& Piccardo, C. (2016). To bid or not to bid: That is the question. Public procurement, project complexity and corruption. European Journal of Political Economy, 43, 89-106. https://doi. org/10.1016/j.ejpoleco.2016.04.002

Bánkuti, M., Halmai, G., \& Scheppele, K. L. (2012). Hun- gary's illiberal turn: Disabling the constitution. Journal of Democracy, 23(3), 138-146. https://doi.org/ 10.1353/jod.2012.0054

Beck, N., \& Katz, J. N. (1995). What to do (and not to do) with time-series cross-section data. American Political Science Review, 89(3), 634-647.

Blackburn, K., \& Forgues-Puccio, G. F. (2009). Why is corruption less harmful in some countries than in others? Journal of Economic Behavior \& Organization, 72(3), 797-810. https://doi.org/10.1016/j.jebo.2009. 08.009

Calderoni, F., Brunetto, D., \& Piccardi, C. (2017). Communities in criminal networks: A case study. Social Networks, 48, 116-125.

Charron, N., Dahlström, C., Fazekas, M., \& Lapuente, V. (2017). Careers, connections, and corruption risks: Investigating the impact of bureaucratic meritocracy on public procurement processes. Journal of Politics, 79(1), 89-103. https://doi.org/10.1086/687209

Charron, N., Dijkstra, L., \& Lapuente, V. (2015). Mapping the regional divide in Europe: A measure for assessing quality of government in 206 European regions. Social Indicators Research, 122(2), 315-346.

Coviello, D., \& Mariniello, M. (2014). Publicity requirements in public procurement: Evidence from a regression discontinuity design. Journal of Public Economics, 109, 76-100.

Croissant, Y., \& Millo, G. (2008). Panel data econometrics in R: The plm package. Journal of Statistical Software, 27(2), 1-43.

David-Barrett, E., \& Fazekas, M. (2019). Grand corruption and government change: An analysis of partisan favoritism in public procurement. European Journal on Criminal Policy and Research. Advance online publication. https://doi.org/10.1007/s10610-019-09416-4

Diwan, I., Keefer, P., \& Schiffbauer, M. (2016). Pyramid capitalism: Cronyism, regulation, and firm productivity in Egypt (IDB Working Paper Series No. 739). Washington, DC: Inter-American Development Bank.

Djankov, S., Islam, A., \& Saliola, F. (2016). How large is public procurement in developing countries? Peterson Institute for International Economics. Retrieved from https://www.piie.com/blogs/realtimeeconomic-issues-watch/how-large-publicprocurement-developing-countries

Eggers, A. C. (2014). Partisanship and electoral accountability: Evidence from the UK expenses scandal. Quarterly Journal of Political Science, 9(4), 441-472. https://doi.org/10.1561/100.00013140

Fazekas, M., \& Kocsis, G. (2020). Uncovering high-level corruption: Cross-national corruption proxies using government contracting data. British Journal of Political Science, 50(1), 155-164.

Fazekas, M., \& Tóth, I. J. (2016). From corruption to state capture: A new analytical framework with empirical applications from Hungary. Political Research Quarterly, 49(2), 320-334.

Fazekas, M., Tóth, I. J., \& King, L. P. (2016). An ob- 
jective corruption risk index using public procurement data. European Journal of Criminal Policy and Research, 22(3), 369-397. https://doi.org/10.1007/ s10610-016-9308-z

Fierăscu, S. I. (2017). The networked phenomenon of state capture (Unpublished Doctoral dissertation). Central European University, Budapest, Hungary.

Freund, C., Nucifora, A., \& Rijkers, B. (2014). All in the family: State capture in Tunisia (Policy Research Working Paper No. WPS 6810). Washington, DC: The World Bank.

Goldman, E., Rocholl, J., \& So, J. (2013). Politically connected boards of directors and the allocation of procurement contracts. Review of Finance, 17(5), 1617-1648. https://doi.org/10.1093/rof/rfs039

Good, P. I. (2006). Resampling methods: A practical guide to data analysis (3rd ed.). Berlin: Birkhauser.

Hessami, Z. (2014). Political corruption, public procurement, and budget composition: Theory and evidence from OECD countries. European Journal of Political Economy, 34, 372-389. https://doi.org/10.1016/ j.ejpoleco.2014.02.005

Jancsics, D. (2015). "A friend gave me a phone number": Brokerage in low-level corruption. International Journal of Law, Crime and Justice, 43, 68-87.

Kim, S.-J., \& Lee, J. (2019). A percolation-like process of within-organization collective corruption: A computational approach. Business \& Society. https://doi.org/ $10.1177 / 0007650319831630$

Knack, S., Biletska, N., \& Kacker, K. (2017). Deterring kickbacks and encouraging entry in public procurement markets: Evidence from firm surveys in 88 developing countries (Policy Research Working Paper No. 8078). Washington, DC: The World Bank.

Lind, P. G., Gonzalez, M. C., \& Herrmann, H. J. (2005). Cycles and clustering in bipartite networks. Physical review $E, 72(5), 056127$.

Luna-Pla, I., \& Nicolás-Carlock, J. R. (2020). Corruption and complexity: A scientific framework for the analysis of corruption networks. Applied Network Science, 5(1), 1-18.

Luz, R. D., \& Spagnolo, G. (2017). Leniency, collusion, corruption, and whistleblowing. Journal of Competition Law \& Economics, 13(4), 729-766.

Mauro, P. (1998). Corruption and the composition of government expenditure. Journal of Public Economics, 69, 263-279.

Milanovic, B., Hoff, K., \& Horowitz, S. (2010). Turnover in power as a restraint on investing in influence: Evidence from the postcommunist transition. Economics \& Politics, 22(3), 329-361.

Mungiu-Pippidi, A. (2015). The quest for good governance: How societies develop control of corruption. Cambridge: Cambridge University Press.

Nicosia, V., Tang, J., Mascolo, C., Musolesi, M., Russo, G.,
\& Latora, V. (2013). Graph metrics for temporal networks. In Temporal networks (pp. 15-40). Berlin and Heidelberg: Springer.

North, D. C., Wallis, J. J., \& Weingast, B. R. (2009). Violence and social orders: A conceptual framework for interpreting recorded human history. Cambridge: Cambridge University Press.

OECD. (2017). Government at a glance 2017. Paris: OECD.

Olken, B. A. (2007). Monitoring corruption: Evidence from a field experiment in Indonesia. Journal of Political Economy, 115(2), 200-249.

Opsahl, T. (2013). Triadic closure in two-mode networks: Redefining the global and local clustering coefficients. Social Networks, 35(2), 159-167.

Papachristos, A. V. (2011). The coming of a networked criminology. Advances in Criminological Theory, 17, 101-140.

Pricewaterhouse Coopers. (2013). Identifying and reducing corruption in public procurement in the EU. Brussels: Pricewaterhouse Coopers and Ecorys.

Robins, G., \& Alexander, M. (2004). Small worlds among interlocking directors: Network structure and distance in bipartite graphs. Computational \& Mathematical Organization Theory, 10(1), 69-94.

Rose-Ackerman, S. (2015). Are corrupt elites necessary for corrupt countries? In C. Dahlström \& L. Wangnerud (Eds.), Elites, institutions and the quality of government (pp. 33-48). New York, NY: Palgrave Macmillan.

Rothstein, B., \& Teorell, J. (2008). What is quality of government? A theory of impartial government institutions. Governance, 21(2), 165-190.

Seawright, J., \& Gerring, J. (2008). Case selection techniques in case study research: A menu of qualitative and quantitative options. Political Research Quarterly, 61(2), 294-308.

Shleifer, A., \& Vishny, R. W. (1993). Corruption. The Quarterly Journal of Economics, 108(3), 599-617.

Stark, D., \& Vedres, B. (2012). Political holes in the economy: The business network of partisan firms in Hungary. American Sociological Review, 77(5), 700-722.

Transparency International. (2013). Global corruption barometer 2013. Berlin: Transparency International.

Wachs, J., \& Kertész, J. (2019). A network approach to cartel detection in public auction markets. Scientific Reports, 9(1), 1-10.

Wachs, J., Yasseri, T., Lengyel, B., \& Kertész, J. (2019). Social capital predicts corruption risk in towns. Royal Society Open Science, 6(4), 182103.

World Bank. (2009). Fraud and corruption: Awareness handbook. Washington, DC: World Bank.

Wright, J. (2008). To invest or insure? How authoritarian time horizons impact foreign aid effectiveness. Comparative Political Studies, 41(7), 971-1000. 


\section{About the Authors}

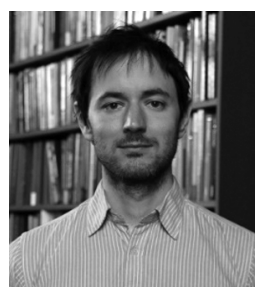

Mihály Fazekas is an Assistant Professor at the Central European University, School of Public Policy, with a focus on using Big Data methods to understand the quality of government globally. He is also the Scientific Director of a think-tank, Government Transparency Institute, while serving as a non-resident Research Fellow at the University of Cambridge. He earned his PhD from the University of Cambridge where he pioneered Big Data methods to measure and understand high-level corruption in Central and Eastern Europe.

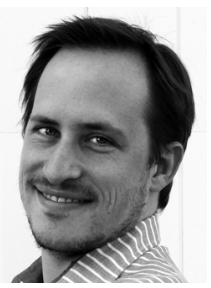

Johannes Wachs is a Postdoctoral Fellow at the Chair for Computational Social Sciences and Humanities at RWTH Aachen University. He obtained his PhD from Central European University in 2019, writing a thesis on the application of network methods to the study of corruption and collusion in procurement markets. He is currently studying online collaboration and cooperation. He has been a visiting researcher at the Oxford Internet Institute, the Hertie School, and the Hungarian Academy of Sciences. 